\title{
Avaliação Pós Ocupação com Ênfase no Conforto Térmico: O Conjunto Habitacional de Oscar Niemeyer no Departamento Tecnológico Aeroespacial
}

\author{
Post Occupancy Evaluation with Emphasis on Thermal Comfort: The \\ Housing Set of Oscar Niemeyer at the Departamento Tecnológico \\ Aeroespacial
}

\section{Evaluación Post Ocupacional con Énfasis en el Confort Térmico: Complejo de Viviendas de Oscar Niemeyer en Departamento Tecnológico Aeroespacial}

SILVA, Leandra Carneiro Marton ${ }^{1}$ ROMÉRO, Marcelo de Andrade ${ }^{2}$ RAMIS, Jacqueline Elhage ${ }^{3}$

1Universidade de Brasília, Faculdade de Arquitetura e Urbanismo, Programa de Pós-Graduação em Arquitetura e Urbanismo. São José dos Campos/SP - Brasil. leandra.marton@gmail.com ORCID: 0000-0002-0172-6642

2Universidade de São Paulo, Faculdade de Arquitetura e Urbanismo, Departamento de Tecnologia da Arquitetura. São Paulo, São Paulo, Brasil marcelo_romero@icloud.com ORCID: 0000-0003-4573-6794

3Instituto Tecnológico de Aeronáutica, Departamento de Engenharia Civil, Programa de Pós-graduação em Infraestrutura Aeronáutica. São José dos Campos, São Paulo, Brasil. jacramis23@gmail.com ORCID: 0000-0002-8218-9227 


\title{
Resumo
}

A presente pesquisa aborda a temática da qualidade do ambiente construído com ênfase na componente térmica e, promove a discussão acerca da importância das questões de conforto no ambiente construído residencial. Para tal, adota-se como objeto deste estudo um exemplar da arquitetura moderna, o bloco habitacional $\mathrm{H}-17$, obra de Oscar Niemeyer, localizado no complexo edificado do campus do Departamento Tecnológico Aeroespacial (DCTA) em São José dos Campos/SP. Assim, a partir da proposição de adequar o conforto e a inércia térmica para a Zona Bioclimática 3 e a fim de orientar recomendações à futuras pesquisas na área da Avaliação Pós Ocupação (APO), ou possíveis intervenções no estudo de caso. Para tal foram desenvolvidos questionário, entrevistas e simulação do desempenho térmico da edificação usando o programa Energy Plus, cujas etapas foram o levantamento de dados e normativas; a aplicação da APO; e a avaliação comportamental e física. Os resultados indicaram um elevado grau de satisfação dos usuários, com insatisfações pontuais, descartando recomendações para futuras intervenções. Contudo a partir da simulação do projeto original constatou-se condições de conforto térmico distantes da Zona de Conforto.

\section{Palavras-Chave: Avaliação Pós-Ocupação; Ambiente Construído; Conforto Térmico; Simulação}

\begin{abstract}
This research addresses the quality of the thermal component of residential buildings and promotes a discussion about the linkage between temperature related issues and thermal comfort in residential buildings. To this end, the object of this study is a model of modern architecture, the $\mathrm{H}-17$ housing block designed by Oscar Niemeyer and located in the campus of the Aerospace Technological Department (DCTA) in São José dos Campos/SP. In order to make recommendations for possible interventions and for the future research in the area of Post Occupancy Evaluation (POE), describes the proposition of adapting comfort and thermal inertia to the Bioclimatic Zone 3. For this purpose, a questionnaire, interviews and simulation of the thermal performance of the building were developed using the Energy Plus program, the research methodology includes the survey of data and regulations, the application of the APO, as well as behavioral and physical assessment. The results indicated a high degree of user satisfaction, with occasional dissatisfaction, discarding recommendations for future interventions. However, from the simulation of the original project, thermal comfort conditions were found below the Comfort Zone.
\end{abstract}

Keywords: Post Occupancy Evaluation; Built Environment; Thermal Comfort; Simulation

\section{Resumen}

Esta investigación acerca del tema de la calidad del entorno construido con énfasis en el componente térmico y promueve una discusión sobre la importancia de las cuestiones de la comodidad en el entorno residencial construido. Para esto, el objeto de este estudio es un modelo de arquitectura moderna, el bloque de viviendas $\mathrm{H}-17$, diseñado por Oscar Niemeyer, ubicado en el complejo del campus del Departamento de Tecnología Aeroespacial (DCTA) en São José dos Campos / SP. Así, a partir de la propuesta de adaptar el confort y la inercia térmica a la Zona Bioclimática 3 y con el propósito de orientar recomendaciones para futuras investigaciones en el área de Evaluación Post Ocupacional (POE), o posibles intervenciones en el caso de estudio. Para ello, se desarrolló cuestionario, entrevistas y simulación del comportamiento térmico del edificio utilizando el programa EnergyPlus, cuyos pasos fueron el relevamiento de datos y normativa; la aplicación de la APO; y evaluación física y del comportamiento. Los resultados indicaron un alto grado de satisfacción del usuario, con insatisfacción ocasional, descartando recomendaciones para futuras intervenciones. Sin embargo, a partir de la simulación del proyecto original, las condiciones de la comodidad térmica se encontraron lejos de la Zona de Confort.

Palabras clave: Evaluación Post Ocupacional; Entorno Construido; Comodidad térmica; Simulación 


\section{Introdução}

\subsection{A Avaliação Pós-Ocupação (APO) do ambiente construído}

No Brasil, a APO tem se consolidado paulatinamente no processo de produção projetual ao permitir o conhecimento sistematizado acerca do ambiente construído, bem como da relação ambientecomportamento humano. Neste sentido, a "complexidade das relações do homem com os seus ambientes físico e social induz a delimitação do tema aqui proposto" (ROMERO, 2013, p.12), ao comprometer-se com o desempenho do ambiente construído e ao atendimento das demandas subjetivas e objetivas do usuário no uso do espaço (ONO et al., 2018, p.25; apud Elali; Veloso, 2004). No entanto, na esfera do poder público esse tema ainda carece de ação e efetivo investimento em novos projetos, bem como para a reabilitação de ambientes construídos púbicos voltados para atividades variadas. Ao considerar esta lacuna, esta pesquisa adota como objeto de estudo um patrimônio público caracterizado como Próprio Nacional ${ }^{1}$, as unidades habitacionais do bloco tipo $\mathrm{H} 17$, do complexo edificado do Departamento Tecnológico Aeroespacial (DCTA).

A edificação, obra do arquiteto modernista Oscar Niemeyer (PENEDO, 1997), integra um conjunto arquitetônico de caráter público, habitacional, e de valor histórico, "em processo de estudo no Instituto do Patrimônio Histórico e Artístico Nacional (IPHAN) para o futuro reconhecimento como patrimônio cultural nacional" (SANCHES, 2020). Entretanto, para Ornstein et al. (2018) é possível identificar falhas de caráter teórico-conceitual acerca das reais necessidades dos usuários nos ambientes construídos concebidos neste período. A gestão da qualidade destes ambientes e as constantes alterações climáticas geram um problema desafiador neste domínio. A requalificação de edifícios torna-se uma questão chave para a manutenção da vida útil dos projetos (VUP) e à garantia do compromisso ambiental. Faz-se urgente que as edificações vislumbrem o futuro acompanhando esta nova realidade. Preconizando a adaptabilidade das edificações a um clima imprevisível sem deixarem de ser confortáveis e sensíveis às necessidades humanas, mas "resilientes e adaptáveis" (HEYWOOD, H, 2015, p.07).

Heywood, H. (2015) considera que uma edificação bem projetada proporciona ambientes internos com condições próximas à zona de conforto humano ao longo do ano inteiro ou pelo maior período possível. No decorrer da sua vida útil, além de atender às necessidades dos usuários, é preciso promover a sustentabilidade do ambiente construído e acompanhar as novas necessidades dos usuários, integrando-as às diferentes fases do ciclo de vida do ambiente (ORNSTEIN et al., 2018). Estima-se que o ser humano passe cerca de $90 \%$ de seu tempo no interior das edificações (HEYWOOD, H, 2015), o que reforça a importância do desempenho dos ambientes construídos para a qualidade de vida do ser humano (LEITNER et al., 2018) e sublinha o compromisso ambiental inerente ao ato de projetar. Para Romero (2013), a arquitetura determina as "condições ambientais, do meio natural e construído, que melhor satisfaçam às exigências do conforto térmico do homem" (ROMERO, 2013, p.12). Em razão deste contexto, se dá a escolha pelo enfoque no ambiente térmico, fundamentada na importância que há para edificações localizadas em regiões subtropicais (ROMERO, 2013), caso do objeto deste estudo.

Com o intuito de promover a discussão acerca da subjetividade das condições de conforto térmico humano, esta pesquisa assume o propósito de verificar a qualidade do ambiente construído visando possíveis futuras reformas e retrofits na edificação. Para tal, utiliza-se o método da APO junto ao uso da simulação de desempenho térmico. Segundo Leitner et al. (2018, p.03) "avaliar é essencial para fechar um ciclo de processo de projeto e confirmação de que as metas foram atingidas" e a aplicação

\footnotetext{
1 É o imóvel de domínio da União utilizado em serviço público federal, para instalação de Órgãos vinculados à Administração Pública Federal direta ou indireta. (UFSC, 2016)
} 
da APO permite a melhoria efetiva da inter-relação entre os fatores ambientais e do ambiente construído, ao fornecer as múltiplas variáveis que interagem nas relações entre ambiente construído e comportamento humano (LEITNER et al., 2018), garantindo assim ao usuário o conforto térmico adequado para o desempenho de suas atividades (ROMERO, 2013).

A relevância do ambiente construído no processo de desenvolvimento humano tem motivado novos estudos que se concentram em propor conceitos, metodologias de pesquisa e de intervenções capazes de criar ambientes adaptáveis as múltiplas demandas humanas. Neste contexto, destaca-se para Ornstein et al. (2018) a metodologia da APO, um conjunto de procedimentos metodológicos que propõem avaliar sistematicamente $\mathrm{O}$ atendimento às necessidades objetivas e subjetivas do usuário durante a vida útil do ambiente construído.

Para a APO, o objeto central é o próprio ambiente construído, em sua escala real e sujeito às necessidades ou níveis de satisfação de seus usuários (LEITNER et al., 2018). De tal modo que a "eficiência de soluções projetuais derivadas da interpretação arquitetônica dos princípios da Física pode ser comprovada, quantificada e aprimorada" (SOARES et al., 2015, p. 297). Assim, a aplicação desta metodologia permite o conhecimento das percepções do utilizador, bem como a compreensão de suas demandas atuais (BARRIENTOS, 2014). Barrientos (2004, p.118) aponta que não apenas o uso do edifício, mas inclusive as condições técnicas devem "atender as expectativas psicocomportamentais dos usuários". O autor entende ser preciso coletar, avaliar e interpretar sistematicamente as informações obtidas, não apenas à nível físico, como também no nível comportamental, para que as intervenções no ambiente atendam ao objetivo de otimizar as condições humanas.

\subsection{Espaço e percepção dos usuários}

A arquitetura busca definir as condições ambientais, do meio natural e construído, que melhor satisfaçam às exigências da zona de conforto térmico humano (ROMERO, 2013). Como aponta Villa, Ono e França (2018), o homem julga constantemente o ambiente ao seu redor por meio da percepção de vivências, necessidades e do ambiente físico, natural ou construído. Para Barrientos (2004) não é o homem quem deve se adaptar ao ambiente e, sim o ambiente que deve atender suas necessidades. $\mathrm{A}$ autora, entende ainda que, o ser humano busca satisfazer cinco necessidades humanas - fisiológicas, segurança, sociais, estima e autorrealização, sendo a fisiológica fundamental para sua sobrevivência. Barrientos (2004) apud Kruger (1996) defendem que a habitação é considerada uma necessidade de ordem fisiológica. Deste modo, a psicologia ambiental em conjunto com a arquitetura avalia e busca explicações para a melhor solução de adaptabilidade do homem ao ambiente construído.

Ao analisar os elementos e fatores que condicionam o ambiente em que o homem desenvolve suas atividades, Romero (2013, p.48) observa que o homem "não é um elemento passivo", uma vez que seu corpo realiza processos de trocas térmicas para estabelecer o equilíbrio térmico e conservar a temperatura interna do corpo próximo a $37^{\circ} \mathrm{C}$. A autora, aponta que os elementos climáticos temperatura, radiação, umidade e movimento do ar atuam na percepção térmica do usuário, ressaltando a relevância da qualidade do desempenho térmico do ambiente e da manutenção das condições dentro da zona de conforto, compreendida entre o intervalo de temperaturas e umidade relativa do ar em que o corpo humano se encontra em equilíbrio térmico com o meio. Soares et al., (2015) observam que a redução do impacto ambiental de edifícios deve estar atrelada a diminuição da chamada energia operacional e, frente ao contexto climático atual, destacam a importância da reabilitação de edificações habitacionais, em especial, na esfera das edificações públicas. 


\subsection{Parâmetros brasileiros de desempenho habitacionais}

Dentre os parâmetros habitacionais brasileiros considerados neste estudo, estão a NBR 15220 e NBR 15575. Tais normativas apresentam diretrizes compatíveis com a VUP², indicando características de desempenho de materiais e sistemas, além de indicar requisitos, critérios e métodos para a avaliação do desempenho térmico por simulação computacional.

A NBR 15220 exibe as propriedades termofísicas dos materiais, os componentes construtivos e diretrizes projetuais para o desempenho térmico de edificações habitacionais unifamiliares de interesse social (ABNT, 2003), além de apresentar o Zoneamento Bioclimático brasileiro e indicar um conjunto de recomendações de caráter técnico-construtivo para cada. Enquanto a NBR 15575 apresenta requisitos a serem atendidos para o desempenho de edificações, como critérios de segurança, de habitabilidade, de sustentabilidade, de conforto e dentre outros, conceituando parâmetros mínimos de qualidade para o ambiente construído (ABNT, 2013). Para a avaliação do desempenho térmico a NBR 15575 recomenda o uso do programa computacional EnegyPlus sob condições de exposição ao clima, de forma a reproduzir os efeitos da inércia térmica dos materiais construtivos, validados pela ASHRAE Standard 140. Quanto aos critérios e limites de aceitabilidade térmica diários para o longo do ano, a NBR 15575 determina: Verão - temperatura interna máxima, menor ou igual a temperatura externa máxima. Inverno - temperatura interna mínima, maior ou igual a $3^{\circ} \mathrm{C}$ acima da temperatura externa mínima.

\subsection{Etapas da pesquisa}

Esta pesquisa dividiu-se em três etapas conforme apresentado a seguir.

A primeira etapa dedica-se a definição do objeto de estudo, do levantamento fotográfico e de dados do projeto original incluindo documentações técnicas junto a Prefeitura Aeronáutica de São José (PASJ) e ao IPHAN, de forma a garantir a caracterização arquitetônica, o valor histórico e o clima local.

A segunda etapa aplicação do método da APO ao objeto de estudo sob aspectos comportamentais e físicos - através da simulação térmica, e apresentação do diagnóstico, onde são comparados.

A terceira etapa propõe recomendações para futuras pesquisas na área da APO e possíveis intervenções no objeto de estudo, considerando se tratar de um conjunto edificado em processo de tombamento junto ao IPHAN.

\section{O Estudo de caso}

$\mathrm{O}$ objeto deste estudo, o conjunto residencial $\mathrm{H} 17$, é composto pelos blocos $\mathrm{H} 17-\mathrm{B}$ e $\mathrm{H} 17-\mathrm{C}$ e integra o complexo edificado do campus do DCTA, em São José dos Campos/SP. Concebido pelo arquiteto Oscar Niemeyer em 1947 materializa uma arquitetura arrojada e traduz o espírito vanguardista da época (FIGUEIREDO, 2019), com partido arquitetônico predominantemente modernista, foi o primeiro bloco residencial a ser construído $(\mathrm{MORI}, 2013)$. Para atender às necessidades hierárquicas do DCTA, buscou-se a diferenciação da forma das edificações, garantindo identidade ao conjunto (PENEDO, 1997).

\subsection{Caracterização arquitetônica do complexo}

O bloco projetado com desenho distinto das demais residências do campus (PENEDO, 1997) é composto por 18 unidades residenciais geminadas por bloco, conforme Figura 1, totalizando 36 unidades, cada uma com área construída de 268 m² (FIGUEIREDO, 2019). 
Figura 1: Fachada principal do conjunto de blocos $\mathrm{H} 17$ no DCTA

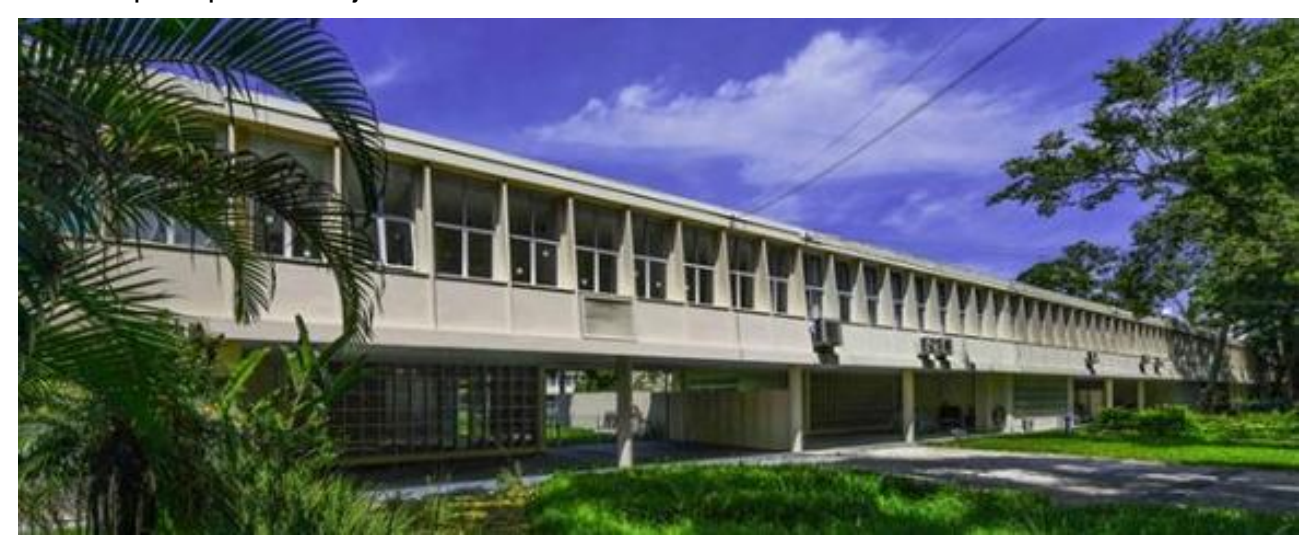

Fonte: Valenews (2021)

O programa de necessidades distribuiu-se em dois pavimentos e em função da adoção de pilotis na estrutura, apresenta volumes marcantes, de forma a criar uma projeção no pavimento térreo, resultando em uma varanda coberta na entrada principal, acompanhada de jardim lateral responsável por interligar as áreas ajardinadas da frente e do fundo do bloco. No andar térreo encontram-se o setor social e de serviço, enquanto o $1^{\circ}$ pavimento é destinado ao setor íntimo. A Figura 2 apresenta a distribuição dos ambientes propostas no projeto original e destacado em verde as áreas a serem avaliadas na simulação.

Figura 2: Planta baixa esquemática de unidade geminada do H17-B

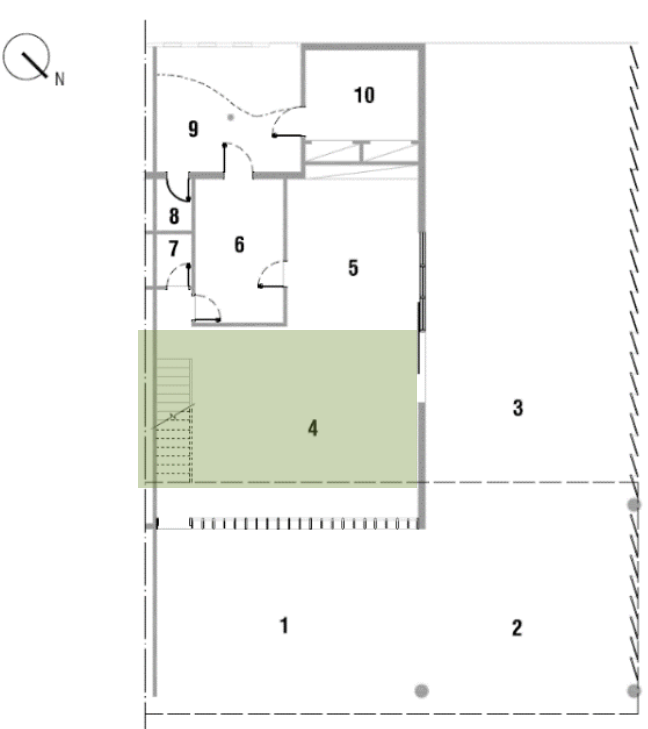

PLANTA BAIXA - TÉRREO

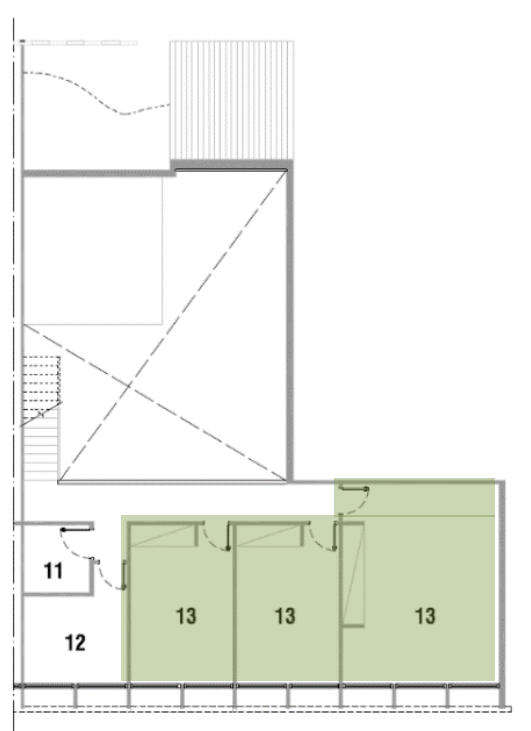

PLANTA BAIXA - $1^{\circ}$ PAVIMENTO

Fonte: Autores (2021)

LEGENDA

1 IVARANDA

2 I GARAGEM

3 I JARDIM LATERAL

4 I SALA DE ESTAR

5 I SALA DE JANTAR

6 I COZINHA

7 I LAVABO

8 I SANITÁRIO SERVIÇO

9 I LAVANDERIA

10 I QUARTO SERVIÇO

1 I ROUPARIA

2 I BANHEIRO

13 I DORMITÓRIOS

Visando reforçar o conceito de permeabilidade e trazer fluidez ao ambiente construído, observa-se a adoção de elementos vazados e "caixilhos de piso ao teto, estabelecendo uma relação de continuidade entre o interior e o exterior da residência" (MORI, 2013 apud IPHAN, p.33), destacando-se a modulação ritmada dos caixilhos do térreo - Figura 3, e primeiro pavimento, inclusive dormitórios e banheiro. No aspecto construtivo, Figueiredo (2013) observa o uso misto predominante do concreto armado e alvenaria de vedação. Para a estrutura o arquiteto propôs o concreto armado, adotado também nas lajes de cobertura, tijolo furado de barro nos vedos opacos e cobertura do tipo borboleta. 
Figura 3: Vista interna da sala de estar

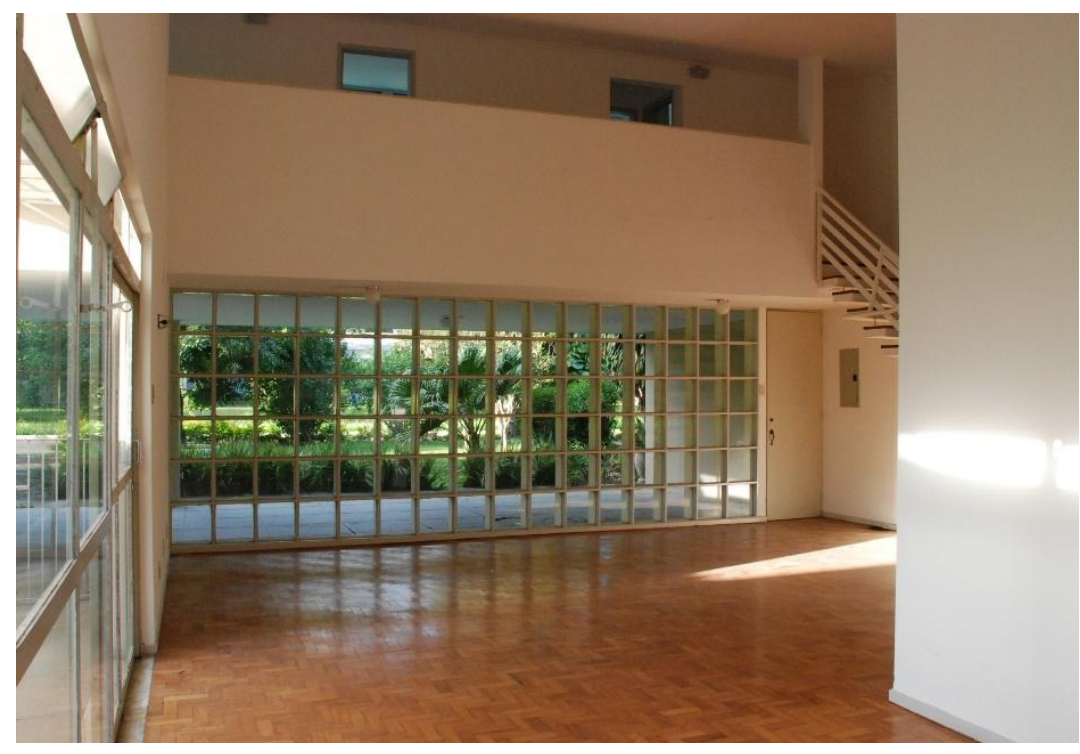

Fonte: IPHAN (2013)

Dentre os últimos trabalhos desenvolvidos sob o mesmo recorte, identificou-se o Projeto Habitas, que comtempla o retrofit de uma das unidades do bloco - $n^{\circ} 104$, sob a perspectiva da certificação AQUAHQE (REIS, 2020). Assim como esta pesquisa, buscou preservar o projeto arquitetônico original e a incorporação de tecnologias sustentáveis aliadas às normas vigentes, que se adequem às características propostas pelo arquiteto, contribuindo para a promoção da sustentabilidade na esfera do patrimônio público.

\subsection{Alterações no projeto original do conjunto}

Para Barrientos (2004) com a ocupação da edificação inicia-se o processo de modificações no ambiente estendendo-se por toda VUP. Em edificações semelhantes e de modo sistêmico, os dados da APO podem a médio e longo prazo, compor bancos de dados que abriguem aspectos positivos e negativos, assim como estratégias por tipo de edificação ou uso, visando especialmente sua reabilitação e a melhoria na qualidade de projetos futuros.

Figueiredo (2019) aponta que durante a etapa de uso e operação, as unidades do $\mathrm{H} 17$ foram as que mais receberam modificações no projeto original. Dentre as principais mudanças observadas destacam-se: ampliação da área construída, como dormitório extra no térreo, transformação da laje de cobertura na área de lazer, avanço da área de varanda para ampliação da sala, fechamento das áreas de jardim, inclusão de iluminação e aparelhos de ar-condicionado. $O$ autor associa as alterações ao fato de serem destinadas aos usuários por curtos períodos de ocupação.

\section{O método ${ }^{3}$ da APO adotado nesta pesquisa}

Villa, Ono e França (2018) sublinham que para a aplicação da APO, além dos parâmetros estabelecidos pelas normativas e dos procedimentos de quantificação e qualificação de desempenho, deve-se também considerar para análise fatores de ordem cultural, econômica, climática e tecnológica. Sabe-se, portanto, que avaliar é essencial para o ciclo de processo de projetual e para a confirmação de que suas metas foram atingidas (LEITNER et al. 2018).

3 Para maiores informações e acesso aos arquivos de dados da avaliação física e comportamental, requerer junto aos autores. 


\subsection{A Avaliação comportamental}

a. aplicação de questionário avaliativo: aplicação de questionário aos atuais moradores e exmoradores, por meio eletrônico - plataforma Google Forms. Para tal, adotou-se questões estruturadas e não estruturadas, e categorizadas em: I-características do entrevistado, IIfuncionalidade, III-acessibilidade, IV-segurança, V-conforto, VI-arquitetônico, VII-manutenção e conservação e VIII-qualidade de vida.

b. entrevista com questões abertas: realização de entrevistas junto ao coordenador do Projeto Habitas, e arquitetos do DCTA e PASJ.

\subsection{A Avaliação física}

A avaliação física visa subsidiar a avaliação comportamental, de forma a fornecer dados que viabilizem uma clara compreensão da percepção dos usuários e foi dividida em quatro etapas, a saber:

a. levantamento dos parâmetros de conforto: aferição dos parâmetros de conforto humano e de desempenho térmico, indicados nas normas brasileiras - NBR 15220, NBR 15575.

b. definição da geometria do modelo: para o modelo considerou-se o projeto original, como um todo, de uma das unidades habitacionais - $n^{\circ} 104$, e foram definidas duas zonas térmicas: zona 1 - térreo (sala de estar) e zona $2-1^{\circ}$ pavimento (dormitórios), para a análise do ambiente.

c. levantamento de dados inputs: referente às características da geometria do edifício, dados climáticos locais - sendo eles: temperatura de bulbo seco (TBS), umidade relativa (UR), ventos, especificações dos componentes - materiais e características termo físicas que compõem a envoltória da edificação, além de características físicas da malha urbana. Os dados climáticos adotados, encontram-se no site http://www.climate.onebuilding.org.

d. simulação computacional: adotou-se a ferramenta da simulação térmica, com o apoio do programa EnergyPlus 8.8, para a avaliação física.

\subsection{Diagnóstico}

Esta etapa abrange a investigação, a interpretação e a comparação entre os dados físicos e comportamentais, correspondentes a simulação térmica e a percepção dos usuários respectivamente. Os resultados possibilitam diretrizes à elaboração de recomendações para projetos de reforma no objeto de estudo ou projetos semelhantes, etapa seguinte a esta.

\subsection{Recomendações para o estudo de caso e futuros projetos semelhantes}

Toda APO quando aplicada resulta em uma série de recomendações, uma vez que o conjunto de informações fornecida por uma amostra representativa dos usuários, aliado a uma investigação física adequada do edifício fornecem base real das condições do estudo de caso. Por outro lado, é sensato pensar que uma parte destas recomendações podem ser extrapoladas para estudos de caso semelhantes e sendo assim, o resultado desta pesquisa apontou elementos que podem ser incorporados noutros projetos.

\section{Aplicação da Avaliação comportamental \\ 4.1 Caracterização do usuário e amostra representativa}

A avaliação comportamental se desenvolveu a partir da aplicação do questionário avaliativo aos atuais moradores e aos ex-moradores, a fim de avaliar o nível de satisfação dos usuários com o ambiente construído. Ono e Ornstein (2018) consideram a metodologia de aplicação do questionário um fator decisivo para o sucesso da pesquisa. Ressalta-se que em função do contexto mundial atual pandemia Corona vírus, o questionário foi respondido sem assistência e enviado eletronicamente pela plataforma Google Forms.

Ao todo o questionário obteve resposta de 25 usuários e seu conteúdo estruturou-se em 8 objetos de abordagem: características do entrevistado, funcionalidade, acessibilidade, segurança, conforto, 
arquitetônico, manutenção e conservação e qualidade de vida. De acordo com a pesquisa os usuários têm entre 30 e 60 anos ou mais, tendo residido na edificação em média entre 1 a 5 anos, destacandose $20 \%$ que residiram por 16 anos ou mais. Segundo informações da Subseção de Imóveis (SSIM) do PASJ, atualmente, das 36 unidades apenas 4 delas estão desocupadas.

\subsection{Resultados da avaliação comportamental}

A partir deste momento, enfoca-se questões relativas à funcionalidade, ao conforto, a arquitetura, a manutenção e conservação, e a qualidade de vida, sobretudo as que tendem ao conforto térmico, critério fundamental para a análise da APO conduzida.

No aspecto funcional, questionou-se os níveis de satisfação com os ambientes internos acerca das áreas disponíveis e das temperaturas internas - cozinha, banheiros, sala de estar, dormitórios, lavanderia. Dentre os resultados, destaca-se a preferência de $92 \%$ pela sala de estar e de $84 \%$ pelos dormitórios. No extremo, tem-se a cozinha e lavanderia com nível de satisfação inferiores, ambos com $66 \%$. Para os ambientes que se destacaram, sala de estar e dormitórios, como observa-se na Figura 4 , os usuários se mostraram $60 \%$ muito satisfeitos e $68 \%$ satisfeitos respectivamente. Com relação a satisfação à disposição e dimensão dos cômodos, ambas apresentaram um nível de satisfação de $88 \%$. A avaliação dos jardins também se destacou, com uma média de $88 \%$ usuários satisfeitos. Cerca de $52 \%$ avaliaram a residência como ótima em relação a outras habitações em que residiram, os demais $48 \%$ classificaram-na como boa. E $52 \%$ indicaram o hábito de permanecer no ambiente durante o período vespertino/noturno.

Figura 4: Aspecto funcional acerca do nível de satisfação na sala de estar (a) e dormitórios (b)
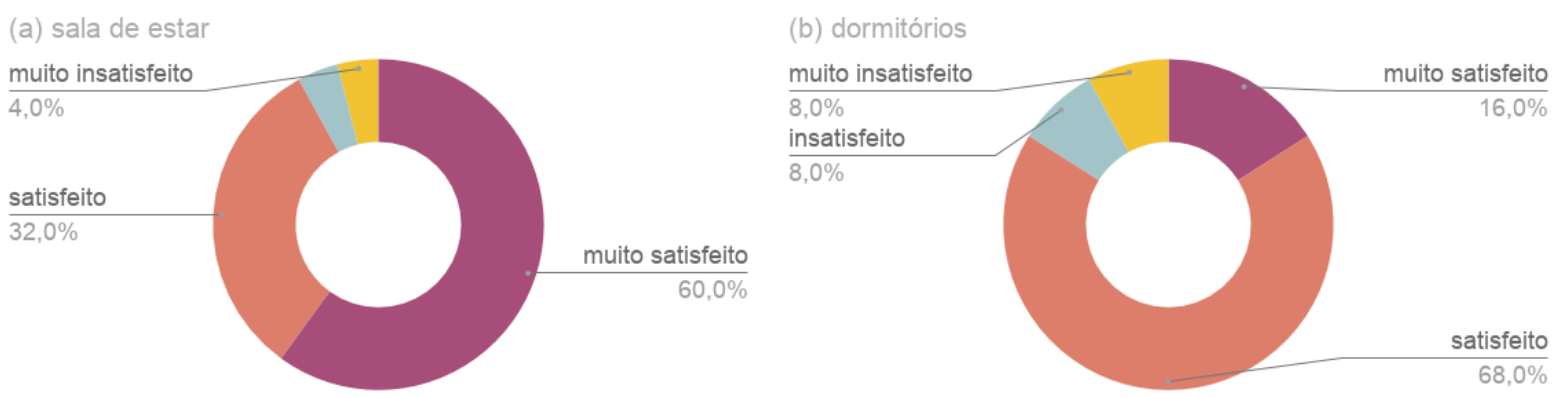

Fonte: Autores (2021)

Para as componentes de conforto, iluminação e ventilação, os resultados apontam que $56 \%$ consideram ótima a iluminação natural e $76 \%$ boa a iluminação artificial na edificação. Quanto a ventilação em geral na habitação, cerca de $92 \%$ mostraram-se satisfeitos, e dentre os ambientes com maior nível de satisfação destacou-se a sala de estar com $88 \%$, seguida pelos dormitórios com $84 \%$.

Quanto ao conteúdo de conforto incialmente buscou-se obter uma perspectiva acerca da sensação térmica nos extremos climáticos. Deste modo, avaliou-se o nível de satisfação com relação a temperatura da habitação como apresentado na Figura 5, onde verificou-se que a maioria dos usuários a avaliam como quente no verão e fria no inverno. Assim sendo, em busca de maior compreensão sob a percepção térmica do usuário aprofundou-se o questionamento aos dormitórios. Conforme indica a Figura 6, apesar de 47,8\% sentirem-se satisfeitos, cerca de $52,10 \%$ demonstraram insatisfação. Destaca-se que $48 \%$ dos respondentes registram o uso de ar-condicionado na edificação, dos $52 \%$ que indicaram não adotar o uso de elemento ativo, cerca de $33,3 \%$ informaram que não sentem necessidade e, $50 \%$ que este não era um item de costume na época em que residiram. 
Figura 5: Avaliação da temperatura da unidade habitacional nas estações verão (a) e inverno (b)
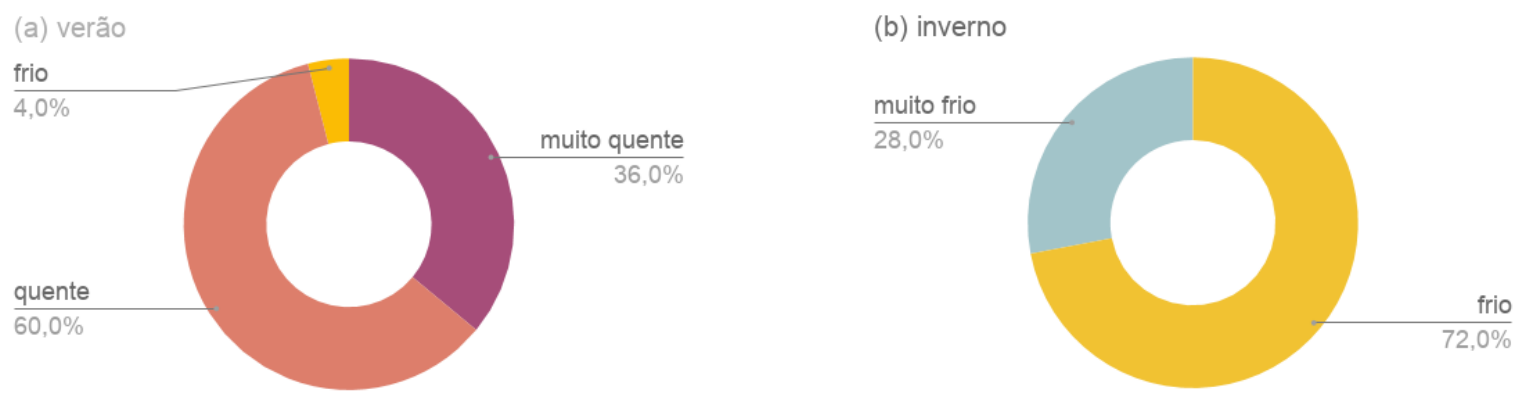

Fonte: Autores (2021)

Figura 6: Avaliação da temperatura nos dormitórios

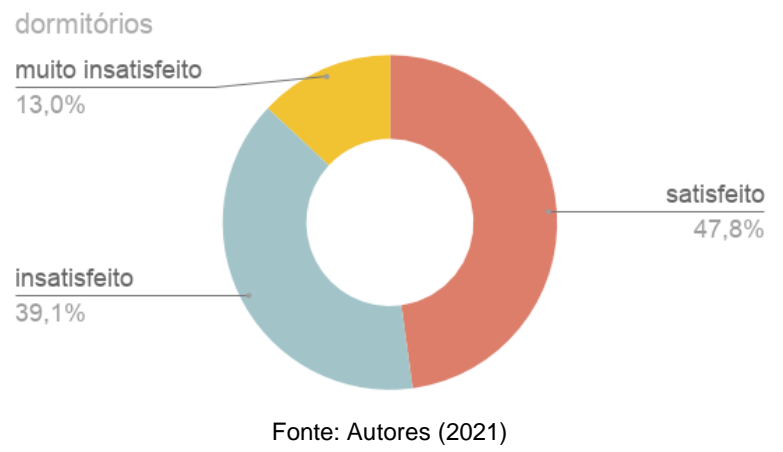

Sob o aspecto arquitetônico, $60 \%$ dos usuários informaram que sua unidade residencial passou por reformas desde sua construção. Dessas alterações, a sala de estar com 56,3\% e dormitórios com $43,8 \%$ e dentre os elementos arquitetônicos destacou-se as portas e janelas.

De forma a entender as motivações das alterações, buscou-se maior compreensão acerca do estado de manutenção e conservação da envoltória (fachada, cobertura e esquadrias) e instalações do patrimônio edificado. Apesar do questionário da APO indicar um grau considerável de modificações nas esquadrias (portas e janelas), quando questionada a qualidade da manutenção e conservação das mesmas, para 47,6\% dos usuários estão em bom estado, como mostra a Figura 7. As coberturas receberam a melhor avaliação, 12\% de usuários a consideraram ótima, entretanto, apresentam a maior média insatisfatória entre os ambientes, cerca de $32 \%$ as consideram péssima/ruim.

Figura 7: Avaliação do nível de manutenção, conservação e operação das esquadrias (a) e cobertura (b)
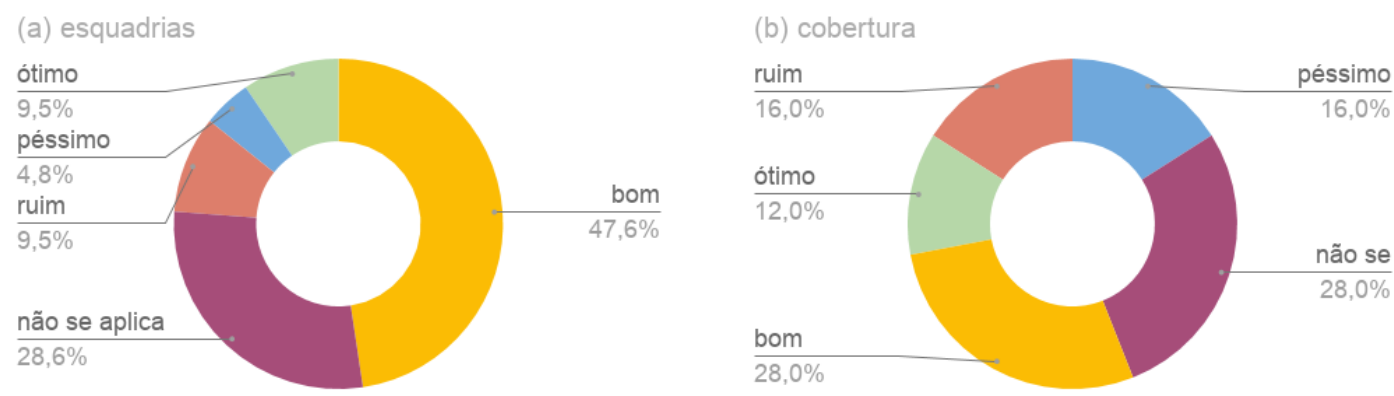

Fonte: Autores (2021)

A partir da Figura 8, obtém-se uma compreensão acerca das atividades consideradas importantes para a qualidade de vida do usuário, sendo possível observar que $28 \%$ deles consideram as áreas externas de extrema influência, acompanhada pelo tamanho e disposição dos ambientes, com $20 \%$. 
Figura 8: Avaliação das atividades relevantes para a qualidade de vida do usuário

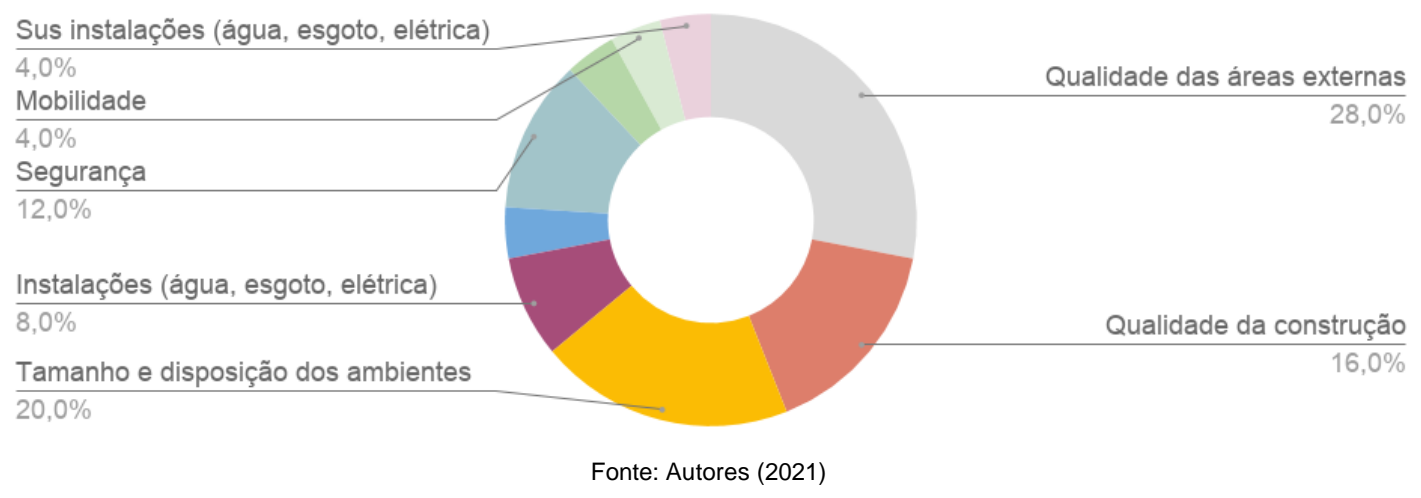

\section{Aplicação da Avaliação Física}

\subsection{Caracterização do contexto climático local}

Romero (2013) sublinha a importância da inter-relação do homem com o ambiente térmico para as regiões subtropicais, contexto climático do território brasileiro. $O$ objeto deste estudo se insere na cidade de São José dos Campos/SP, município pertencente a região Sudeste do país, esta, segundo a NBR 15220, caracterizada como Zona Bioclimática 3 (ZB3) (ABNT, 2003), possui clima ameno e estações bem definidas (CB3E, 2014).

O conhecimento das Zonas Bioclimáticas (ZB) é relevante para o processo projetual, uma vez que a partir do cruzamento de três dados - zona de conforto térmico humano, dados climáticos e estratégias de projeto e construção, é possível se determinar estratégias para atingir o conforto térmico adequado. $\mathrm{Na}$ Tabela 1 apresentam-se as diretrizes construtivas para a ZB3 com o tamanho e sombreamento das aberturas, tipos de vedações externas, estratégias de condicionamento térmico passivo conforme a estação do ano (ABNT, 2003) como forma de garantir a manutenção da inercia térmica.

Tabela 1: Diretrizes construtivas para Zona Bioclimática 3 (ZB3)

\begin{tabular}{|c|c|c|}
\hline ASPECTOS & \multicolumn{2}{|c|}{ ZB 3} \\
\hline TAMANHO ABERTURAS & \multicolumn{2}{|c|}{ Médias $(15 \%<\mathrm{A}<25 \%)$} \\
\hline SOMBREAMENTO ABERT. & \multicolumn{2}{|c|}{ Permitir sol no inverno } \\
\hline \multirow{3}{*}{ PAREDES EXTERNAS } & \multirow{3}{*}{ Leve refletora } & $\mathrm{U} \leq 3,6 \mathrm{~W} / \mathrm{m}^{2} . \mathrm{K}$ \\
\hline & & $\varphi \leq 4,3 \mathrm{~h}$ \\
\hline & & $\mathrm{FS} \leq 4 \%$ \\
\hline \multirow{3}{*}{ COBERTURAS } & \multirow{3}{*}{ Leve isolada } & $\mathrm{U} \leq 3,6 \mathrm{~W} / \mathrm{m}^{2} . \mathrm{K}$ \\
\hline & & $\varphi \leq 3,3 \mathrm{~h}$ \\
\hline & & $\mathrm{FS} \leq 6 \%$ \\
\hline EST.COND. PASSIVO INTERNO & \multicolumn{2}{|c|}{$\begin{array}{l}\text { Aquecimento solar da edif. } \\
\text { Inércia térmica solar }\end{array}$} \\
\hline EST. COND. PASSIVO VERÃO & \multicolumn{2}{|c|}{ Ventilação cruzada } \\
\hline
\end{tabular}

\subsection{Simulação computacional das condições térmicas}

Este estudo avalia o conforto térmico nos ambientes supracitados (Figura 3) a partir da ferramenta da simulação, ao considerar ser imprescindível o conhecimento sobre a influência das variáveis do meio na percepção térmica dos usuários (ROMERO, 2013). Para SOARES et al., (2015) a vantagem do uso de técnicas computacionais aos métodos analíticos, está na possibilidade de uma avaliação térmica que considere variáveis externas, como clima, padrão de ocupação, materialidade e ainda, efeitos da inércia na edificação. O autor aponta ainda que para edificações cujas condições do meio são estabelecidas por técnicas passivas, a simulação possibilita a quantificação desse potencial, e o 
reconhecimento dos períodos em que o ambiente apresenta condições de conforto térmico em conformidade com os parâmetros de desempenho habitacionais adotados (item 1.3).

Para análise comparativa e embasamento do diagnóstico, simulou-se inicialmente um caso base, com modelo geométrico de acordo com o projeto original da unidade 104 do bloco H17-B. Para tal, adotouse uma envoltória simplificada, sem o detalhamento de obstáculos naturais do entorno, com paredes e cobertura como indicados na Figura 9, caracterizando camada a camada, e por fim definiu-se como "suburbs" a área no software Energy Plus. Para as janelas dos ambientes em análise, devido aos padrões das esquadrias, optou-se por considerar as áreas envidraçadas. Com relação as transmitâncias térmicas originais, "capacidade térmica e atraso térmico de algumas paredes e coberturas" (ABNT, 2003, p.01) encontrou-se 2,16 W/m² $\mathrm{K}$ e 2,38 W/m² K respectivamente, ambos em conformidade com os parâmetros definidos pela NBR 15220 (U $\leq 3,6 \mathrm{~W} / \mathrm{m}^{2}$. K). Ainda ao analisar o caso base sob os parâmetros indicados pela NBR 15220, observou-se que o padrão adotado para as aberturas é superior ao recomendado, cerca de $50 \%$ de área de janela em relação a área de piso do ambiente. Vale ressaltar que, as aberturas que sofrem maior incidência da radiação solar direta não possuem qualquer elemento de proteção.

Figura 9: Detalhes construtivos da envoltória - cobertura e paredes
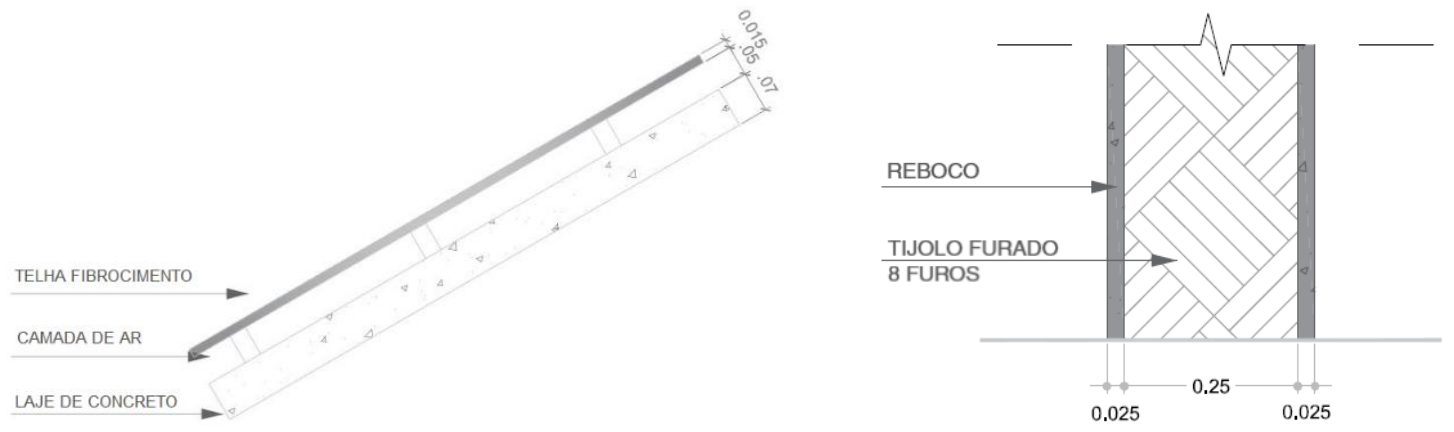

Fonte: Autores (2021)

A simulação do caso base, possibilitou o entendimento do comportamento térmico do ambiente ao longo do ano simulado. Deste modo, os dados apresentados na Figura 10 indicam que as temperaturas externas variaram entre $6^{\circ} \mathrm{C}$ e $34^{\circ} \mathrm{C}$, o que sugere que haja desconforto térmico nos extremos climáticos e evidencia uma considerável carência na uniformidade das temperaturas ao longo dos períodos, especialmente no verão.

Figura 10: Amplitude térmica externa diária

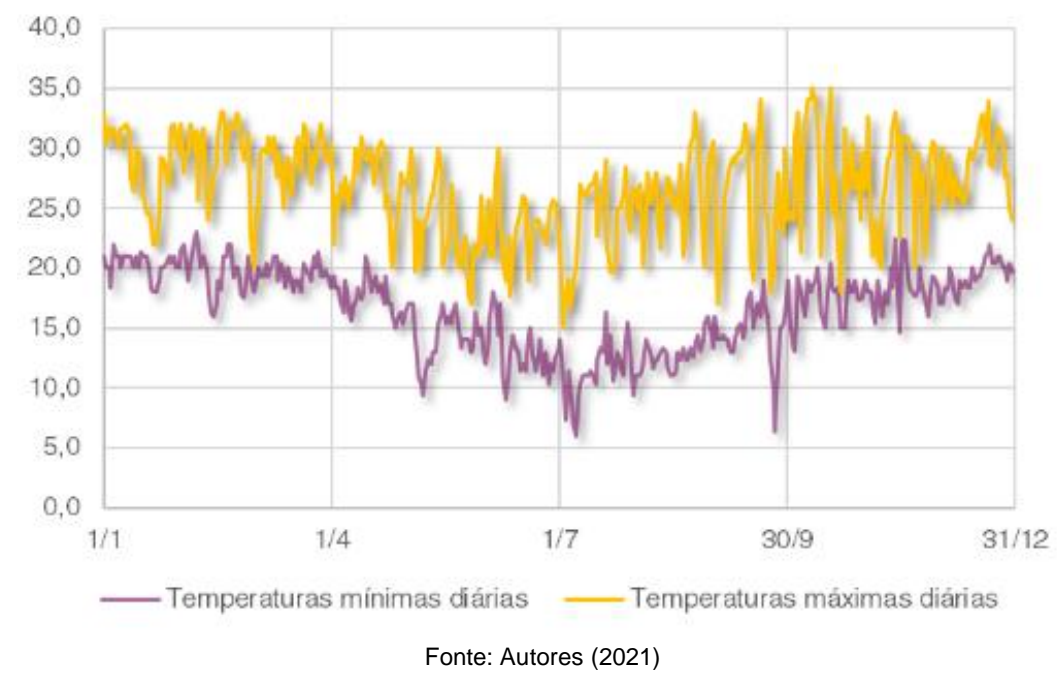


Em seguida, selecionou-se para avaliação física os ambientes que mais se destacaram positivamente na aplicação do questionário da APO: sala de estar (térreo) e dormitórios (1ํppavimento). Assim sendo, para a análise definiu-se duas zonas térmicas: zona 1 - térreo e zona $2-1^{\circ}$ pavimento, e como variáveis: cobertura e esquadrias. Após o levantamento dos dados do caso base, realizou-se a simulação para duas hipóteses de alteração na envoltória visando a melhoria das temperaturas internas. Na primeira, foi proposto o uso de lã de rocha, com resistência térmica de 0,889 $\mathrm{m}^{2} \mathrm{~K} / \mathrm{W}$, na camada de ar entre a laje e a telha de fibrocimento, e para a segunda situação, a substituição da telha fibrocimento por argila expandida, cuja condutividade térmica é de $0,16 \mathrm{~W} / \mathrm{mK}$, e a alteração das janelas da área envidraçada, por vidros com baixa emitância LoE CLEAR 6MM Rev descritos no conjunto de dados WindowGlassMaterials.IDF, disponível no EnergyPlus. A escolha por estes materiais se deve por sua capacidade em controlar o fluxo de calor que atravessam os fechamentos.

Tabela 2: Temperaturas de bulbo seco (TBS) das simulações

\begin{tabular}{|c|c|c|c|c|c|}
\hline \multirow{2}{*}{ TBS MÉDIAS } & \multirow{2}{*}{ SIMULAÇÃO } & \multicolumn{2}{|c|}{ VERÃO $\left({ }^{\circ} \mathrm{C}\right)$} & \multicolumn{2}{|c|}{ INVERNO $\left({ }^{\circ} \mathrm{C}\right)$} \\
\hline & & mínima & máxima & mínima & máxima \\
\hline EXTERNAS & & 16.0 & 33.0 & 6.0 & 34.0 \\
\hline \multirow{3}{*}{$\begin{array}{c}\text { ZONA } 1 \text { - TÉRREO } \\
\text { (SALA) }\end{array}$} & CASO BASE & 23.2 & 36.2 & 15.6 & 33.5 \\
\hline & $\begin{array}{l}\text { ARGILA EXPANDIDA E VIDROS } \\
\text { BAIXA EMITÂNCIA }\end{array}$ & 23.9 & 34.7 & 20.8 & 32.8 \\
\hline & LÃ DE ROCHA & 23.4 & 39.1 & 16.1 & 37.1 \\
\hline \multirow{3}{*}{$\begin{array}{l}\text { ZONA } 2 \text { - 19 PAV. } \\
\text { (DORMITÓRIOS) }\end{array}$} & CASO BASE & 17.8 & 41.8 & 15.5 & 35.1 \\
\hline & $\begin{array}{l}\text { ARGILA EXPÂNDIDA E VIDROS } \\
\text { BAIXA EMITÂNCIA }\end{array}$ & 27.2 & 42.3 & 17.2 & 35.0 \\
\hline & LA DE ROCHA & 26.2 & 54.0 & 16.1 & 48.4 \\
\hline
\end{tabular}

Os resultados encontrados para as médias das temperaturas internas, apresentados na Tabela 2, apontam que ambas as Zonas se enquadram na zona de conforto estabelecida pela NBR 15220, entretanto, em grande parcela do tempo apresentam índices acima ou abaixo dos parâmetros exigidos. Ao comparar a interação entre o caso base e as duas hipóteses de alteração propostas, é possível observar que a proposta de adoção do isolamento térmico da laje com lã de rocha, refletiu na elevação das TBS máximas, gerando uma situação agravada tanto para o verão quanto para o inverno, comportamento oposto ao desempenho apresentado na adoção da argila expandida e vidro de baixa emitância, onde as temperaturas máximas no interior das Zonas se mostraram mais uniformes ao longo do ano, como também é possível observar a partir dos resultados apresentados nas Figuras $11 \mathrm{e}$ 12.

Dentre as hipóteses propostas, destacou-se o desempenho encontrado na simulação com argila expandida e vidro, devido a menor variação entre os extremos para ambas as zonas - 1 e 2 , além de valores de mínimas e máximas mais próximas as da zona de conforto humano. Para a Zona 1, como apresentam as Figuras 11 e 12, as mínimas diárias mantem-se próximo a zona de conforto ao longo do período, dentre as hipóteses simuladas, ambas apresentaram um desempenho similar ao caso base, mas dentre eles, a argila expandida aliada ao vidro com baixa emitância apresentou temperaturas próximas as da zona de conforto, variando entre $20,8^{\circ} \mathrm{C}$ a $32,8^{\circ} \mathrm{C}$. 
Figura 11: Temperaturas mínimas diárias Zona 1 - sala de estar

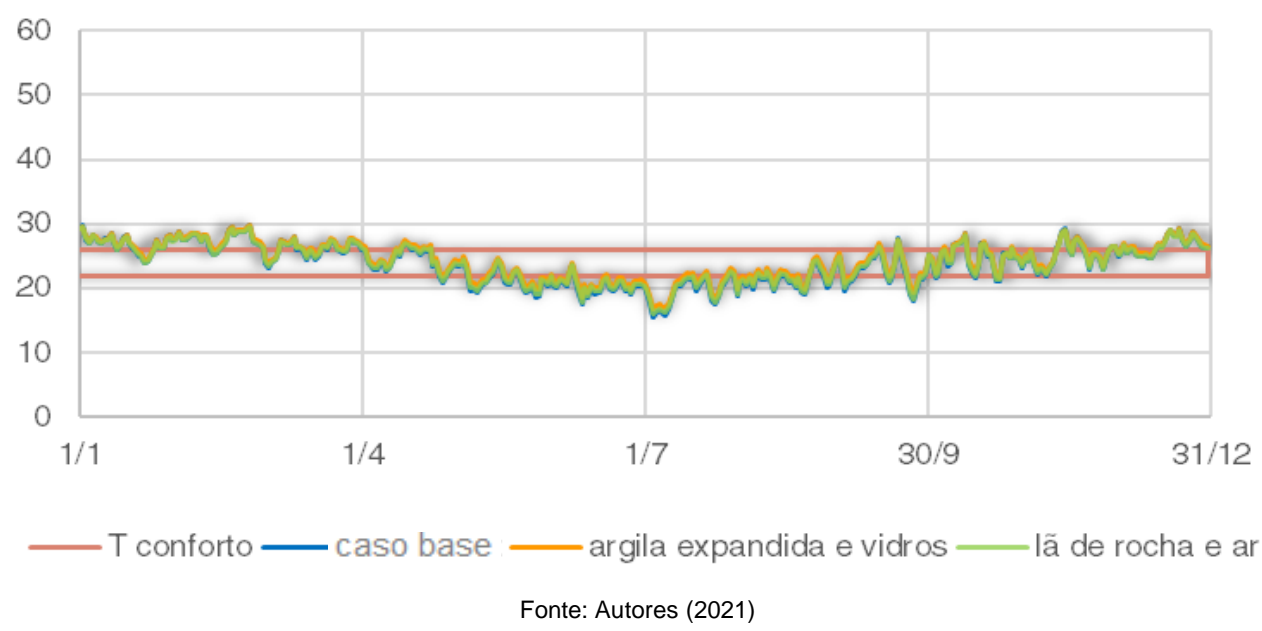

Para as temperaturas máximas diárias, novamente o desempenho da argila expandida e vidro se mostrou relevante, mesmo apresentando um comportamento próximo ao do caso base. Já a lã de rocha não demonstrou relevância para a melhoria da qualidade térmica do ambiente construído.

Figura 12: Temperaturas máxima diárias Zona 1 - sala de estar

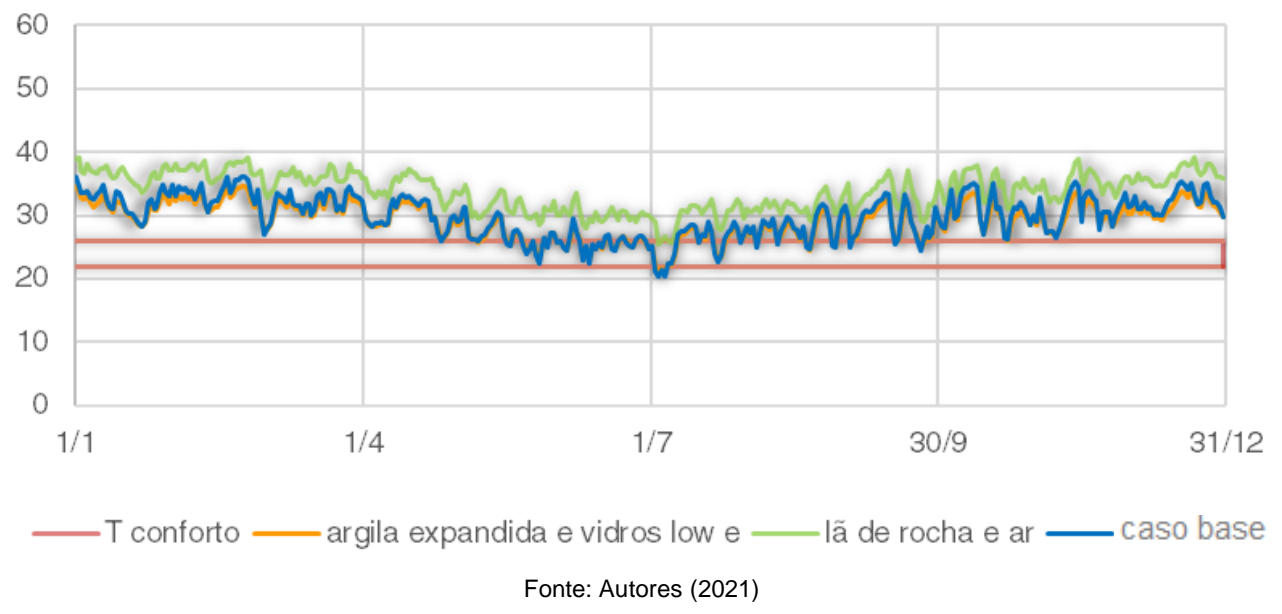

A seguir, a partir das Figuras 13 e 14, é possível observar o comportamento térmico das hipóteses simuladas para a Zona 2. Nesta Zona, o caso base apesar de apresentar grande amplitude térmica no verão, exibiu as menores temperaturas para verão e inverno (Tabela 2). Já a hipótese da argila expandida e vidro de baixa emitância indicou um o desempenho considerável para qualidade do conforto térmico, embora ofereça uma temperatura máxima elevada para o verão, para o inverno, apresentou as temperaturas mais adequadas a zona de conforto humana, além de ser a solução menor amplitude térmica ao longo do período. O desempenho da lã de rocha associada a laje de concreto influenciou diretamente na elevação das temperaturas nos dormitórios ao longo do ano, tanto no verão $-54^{\circ} \mathrm{C}$, quanto inverno $-48,4^{\circ} \mathrm{C}$ (Tabela 2), além do agravamento da situação, apresenta as maiores amplitudes térmicas, gerando uma baixa qualidade térmica aos usuários. 
Figura 13: Temperaturas mínimas diárias Zona 2 - dormitórios

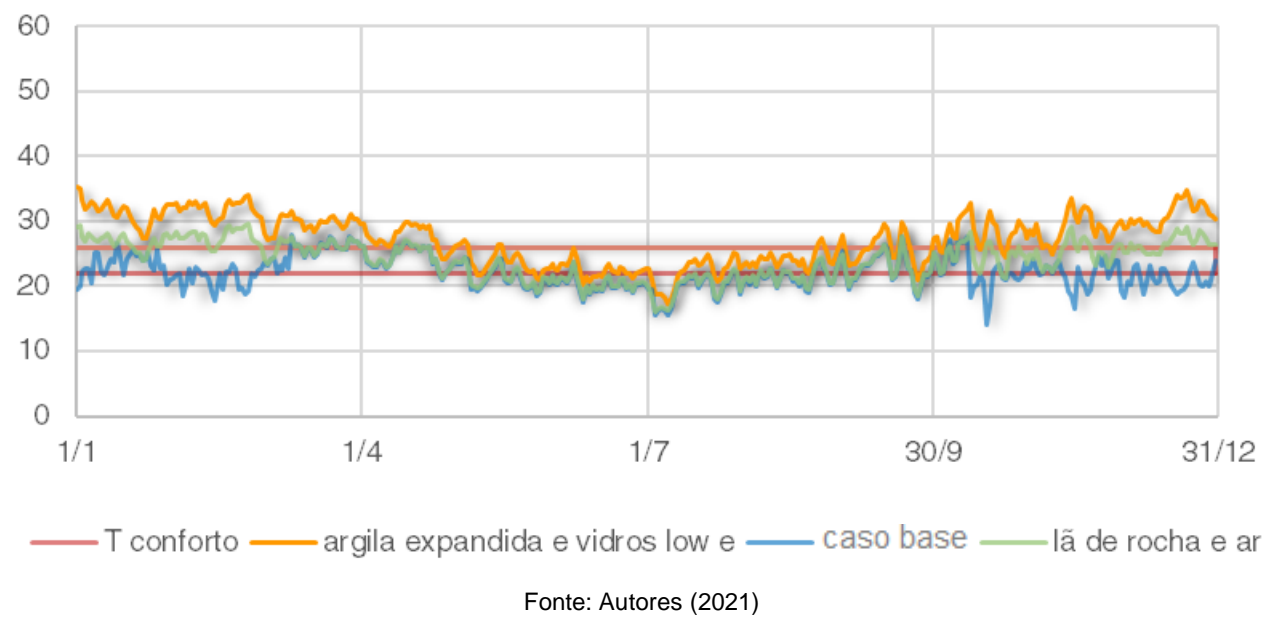

Figura 14: Temperaturas máxima diárias Zona 2 - dormitórios

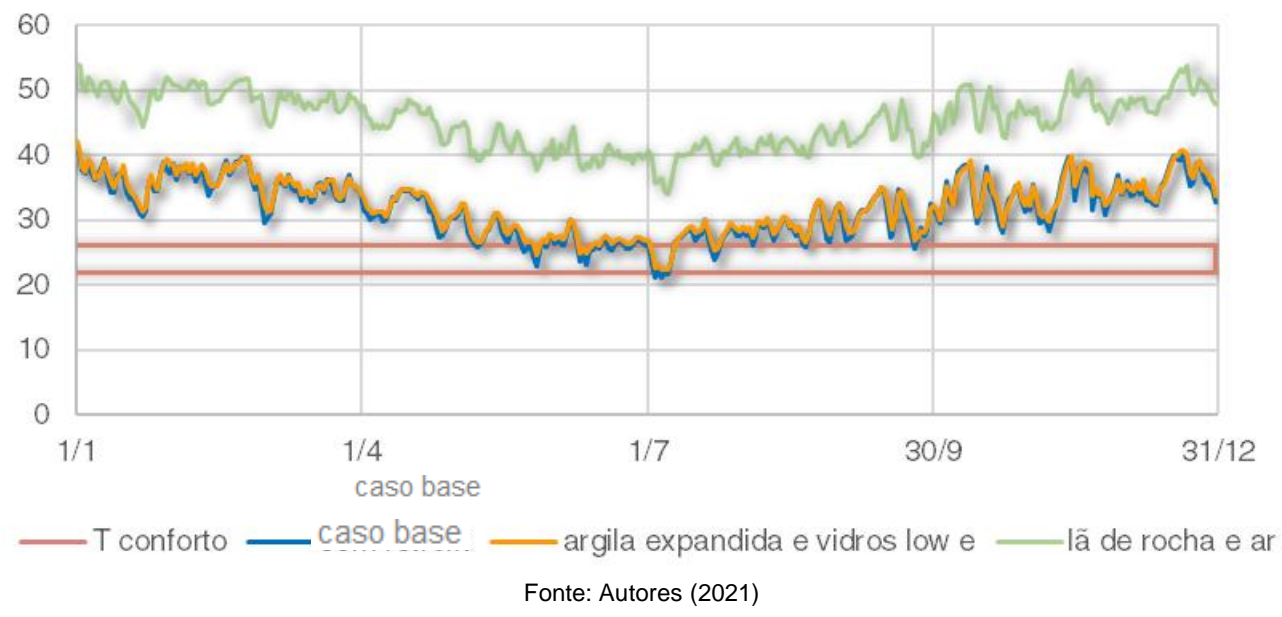

\section{Diagnóstico}

A partir da APO, da percepção do usuário, das condicionantes do meio e apoio da análise da avaliação física e comportamental, possibilitou-se uma compreensão de forma integral acerca da relação homem e ambiente construído com o objeto deste estudo. Os resultados obtidos revelaram problemas associados ao conforto térmico nos dormitórios devido aos aspectos construtivos da cobertura e de adequação ao uso atual.

Os resultados satisfatórios encontrados na avaliação comportamental para os ambientes selecionados - sala de estar e dormitórios, quando comparados aos dados encontrados na avaliação física, tornam questionáveis a percepção térmica dos usuários, uma vez que encontrou-se nos ambientes temperaturas acimas de $40^{\circ} \mathrm{C}$, extremamente desconfortável para o conforto humano, de acordo com os parâmetros preestabelecidos no item 1.3. O desconforto dos usuários com a percepção térmica durante $o$ verão e o inverno pode se justificar pela amplitude térmica encontrada no caso base, variando entre $15,6^{\circ} \mathrm{C}$ e $41,8^{\circ} \mathrm{C}$, não garantindo conforto nos extremos. Para a sala de estar, os resultados do caso base apresentaram temperaturas mais amenas, variando entre $23,2^{\circ} \mathrm{C}$ a $41,8^{\circ} \mathrm{C}$, as temperaturas reforçam a satisfação dos usuários encontrada no questionário. Entretanto, o que se observa nos resultados dos dormitórios é contraditório, apesar do elevado grau de satisfação dos usuários, a avaliação física exibiu temperatura elevadas, com máxima de $41,8^{\circ} \mathrm{C}$, uma vez que a orientação solar da fachada se encontra voltada para nordeste. No entanto, vale destacar que a 
sensação de conforto é extremamente subjetiva e sofre influência de fatores fisiológicos, vestimenta e atividade do usuário.

Dentre as hipóteses simuladas, a argila expandida aliada a adoção de vidros com baixa emitância mostrou um desempenho relevante para as estações ao longo de todo período. Na tentativa de se isolar a laje, sugeriu-se o uso da lã da rocha associada a telha fibrocimento, entretanto tal solução apesar de atender aos critérios de transmitância térmica estabelecidos por norma para a ZB3, aumenta consideravelmente a inercia térmica. Percebe-se que os resultados encontrados nas simulações apresentaram níveis de desempenho próximos ao do caso base, entende-se que a análise dos dados medidos mostrou que alterações pontuais na envoltória por si só não são capazes de determinar o desempenho térmico global do estudo do caso.

No aspecto arquitetônico, os usuários apontaram as esquadrias como elemento arquitetônico com maiores alterações, assim como indicaram grande insatisfação quanto a manutenção e conservação. Conforme apresentado na Figura 15 - (b), no $1^{\circ}$ pavimento o arquiteto adota um padrão das janelas tipo "horizonte infinito", característico da arquitetura da época, contudo um índice importante - WWR (Window to Wall Ratio), assim como as diretrizes da NBR 15220, indicam a proporção de $15 \%$ a $25 \%$ entre a área da janela em relação a de piso do ambiente. Neste caso, em que a proporção das janelas chega a ser superior a 50\%, é considerável a influência nas trocas térmicas entre o ambiente e o meio. De fato, a produção moderna apresentava uma arquitetura que rompia com antigos padrões, ao utilizar novos materiais, e preocupação para com o desenho, em detrimento do conforto do usuário.

Figura 15: Padrão das esquadrias no H17-B - (a) sala de estar e (b) dormitórios

(a)

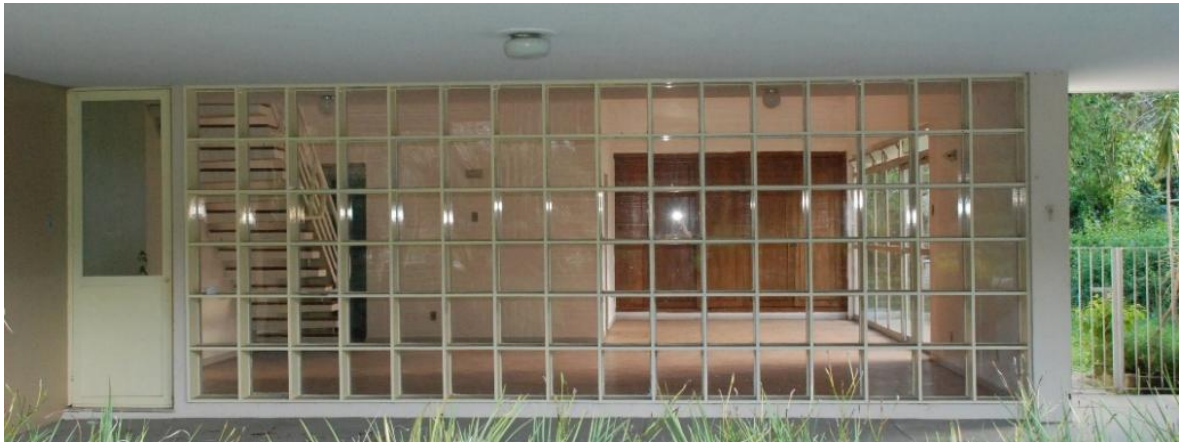

(b)

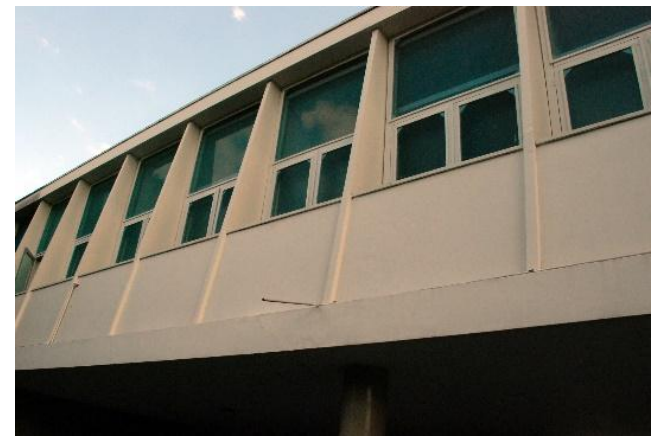

Fonte: IPHAN

\section{Recomendações}

Em virtude dos resultados encontrados, a APO indicou um elevado grau de satisfação dos usuários com os ambientes analisados, entretanto a simulação viabilizou uma compreensão aproximada do comportamento físico do ambiente, permitindo a análise de possíveis orientações de projeto. A partir destes resultados e ao considerar que a percepção térmica pode vir a ser extremamente subjetiva, aponta-se a importância de novas pesquisas na área, visando estratégias projetuais relevantes ao desempenho térmico adequado. 
A APO aplicada mostra-se importante para conduzir orientações a novos estudos sob a metodologia da APO ou mesmo para futuras intervenções no estudo de caso. Surge ainda como um incentivo para o desenvolvimento de um padrão de APO em acordo com à realidade física, funcional e econômica dos ambientes habitacionais no âmbito público. Deste modo, sugere-se:

Com base nos requisitos de desempenho térmico do ambiente construído estabelecidos pela NBR 15220 e considerando os resultados obtidos, recomenda-se a adoção de ventilação mecânica no período noturno para garantir o conforto dos usuários. Apesar do pé direito elevado na sala, o desempenho térmico passivo da residência mostrou-se insatisfatório, tendo em vista que o calor gerado no pavimento térreo tende a subir para o pavimento superior que por sua vez não possui aberturas necessárias para a saída do ar quente.

O padrão de ocupação das unidades habitacionais do bloco $\mathrm{H} 17$, reservado a atender oficiais generais de variadas origens regionais e por curtos períodos - 2 a 3 anos, implica em constantes alterações no ambiente, reforçando a importância de que futuras intervenções considerem as necessidades do usuário, sob perspectiva funcional e cultural, de forma a adotar um modelo padrão de projeto. As possíveis alterações sugeridas para as unidades, devem destacar seu valor histórico e evitar que eventuais modificações venham a interferir no desempenho térmico do ambiente. Entende-se que o processo de tombamento junto ao IPHAN torna os procedimentos de reabilitação ou retrofits mais restritivos, limitando possíveis estratégias de projeto, no entrando o método da APO se faz relevante para reforçar a tomada de decisão sob futuras intervenções, bem como a escolha de tecnologias sustentáveis alinhadas às propostas originais do projeto das unidades habitacionais. Neste sentido, ainda sob a ótica da percepção térmica, sugere-se para um próximo estudo com aplicação da APO a inclusão de questionamento sobre a origem regional do respondente à avaliação comportamental, de forma a permitir uma compreensão mais aprofundada das condições de conforto radicadas em cada usuário.

\section{Conclusões}

A partir dos resultados encontrados e com base no recomendado pela NBR 15220, conclui-se que os padrões adotados na arquitetura moderna naquele momento histórico, não se mostram indicados para a realidade climática da ZB3, especialmente sob a ótica do desempenho térmico. Entende-se que para a época de concepção do projeto, não era usual a adoção da argila expandida, entretanto, observa-se que em um eventual projeto de reabilitação ou retrofit, esta tecnologia mostrou-se bastante viável, não somente do ponto de vista térmico como do energético, financeiro e ambiental. No entanto, o emprego da argila expandida sobre a laje de cobertura reduziu as temperaturas e a amplitude térmica ao longo do ano para os dois pavimentos com melhor desempenho no pavimento superior - dormitórios.

A pesquisa demonstrou que a aplicação de uma APO com ênfase no conforto ambiental e na eficiência energética, é uma excelente ferramenta para a reabilitação ou retrofit de edifícios pois identifica com precisão os aspectos que necessitam de intervenção para a melhoria do conforto térmico dos usuários.

A pesquisa reafirmou o uso e a importância das ferramentas dinâmicas de simulação na etapa do projeto de reabilitação dos edifícios, tendo em vista a facilidade de estudo e aplicação de soluções diversas e o elevado nível de confiabilidade técnicas destas ferramentas. 


\section{Referências}

ASSOCIAÇÃO BRASILEIRA DE NORMAS TÉCNICAS. NBR 15220: desempenho térmico de edificações. ABNT. Rio de Janeiro. 2003.

ASSOCIAÇÃO BRASILEIRA DE NORMAS TÉCNICAS. NBR 15575: desempenho edificações habitacionais. Rio de Janeiro. 2013.

BARRIENTOS, M. I. G. G. Retrofit de Edificações - Estudo de reabilitação e adaptação das novas edificações antigas às necessidades atuais. Rio de Janeiro: [s.n.], 2004. 252 p. Disponivel em: $<$ www.pantheon.ufrj.br/handle/11422/1652>. Acesso em: 2020.

CENTRO BRASILEIRO DE EFICIÊNCIA ENERGÉTICA EM EDIFICAÇÕES - CB3E - UFSC NÚCLEO DE EDIFICAÇÕES COMERCIAIS. Diretrizes para Obtenção de Classificação Nível A para Edificações Comerciais, de Serviços e Públicas. Site PBE Edifica: [s. n.], 2014. Disponível em: http://pbeedifica.com.br/sites/default/files/projetos/etiquetagem/comercial/downloads/Manual-A.pdf.

Acesso em: 10 jul. 2020.

DEVECCHI, A. M. Reformar não é construir - A Reabilitação em Edifícios Verticais - Novas Formas de Morar em São Paulo no Século XXI. São Paulo: Senac, 2014.

FIGUEIREDO, A. R. B. Centro Técnico de Aeronáutica - Os setenta anos do bairro modernista de Niemeyer, Mourão e DIRENG. Brasília, p. 199. 2019.

FIGUEIREDO, Rolando Piccolo. Patrimônio Moderno: A manutenção do ITA de Oscar Niemeyer: Sobre a falsa perenidade do que é simples. In: Patrimônio Moderno: A manutenção do ITA de Oscar Niemeyer: Sobre a falsa perenidade do que é simples. ISSN 2175-6716. Site Vitruvius, 19 mar. 2019. Disponível em: https://www.vitruvius.com.br/revistas/read/drops/19.138/7290. Acesso em: 19 abr. 2020.HEYWOOD, H. 101 Regras Básicas Para Uma Arquitetura de Baixo Consumo Energético. São Paulo: Gustavo Gili - GG, 2015.

FRANÇA, Ana Judite Galbiatti Limongi; ONO, Rosária; ORNSTEIN, Sheila Walbe. A utilização de APO para a melhoria do ambiente construído: APO, desempenho e suas relações com normas e certificações. In: ONO, Rosária; ORNSTEIN, Sheila Walbe; VILLA, Simone Barbosa; FRANÇA, Ana Judite Galbiatti Limongi. Avaliação pós-ocupação (APO): na Arquitetura, no Urbanismo e no Design: da teoria à prática. São Paulo: Oficina de Textos, 2018. cap. 2, p. 49-62.

LEITNER, Andrea D'Angelo; ROMÉRO, Marcelo de Andrade; BARBOSA, Maria Beatriz Pestana; SARAMAGO, Rita de Cássia Pereira; ABATE, Tania Pietzchke. Avaliação pós-ocupação (APO): na Arquitetura, no Urbanismo e no Design: da teoria à prática. São Paulo: Oficina de Textos, 2018.

MORI, Renata Bacheschi. Centro Técnico de Aeronáutica: Do Concurso de Anteprojetos aos Edifícios Esquecidos de Niemeyer. Orientador: Luiz Recamán. 2013. 250 p. Trabalho Final de Graduação (Bacharelado em Arquitetura e Urbanismo) - Universidade de São Paulo, São Paulo, 2013. Disponível em: https://issuu.com/renatabmori/docs/issuu. Acesso em: 19 abr. 2020.

ONO, Rosária; ORNSTEIN, Sheila Walbe. Fundamentos de APO: Método quantitativo para a aferição da percepção dos usuários. In: ONO, Rosária; ORNSTEIN, Shiela Walbe; VILLA, Simone Barbosa; FRANÇA, Ana Judite Galbiatti Limongi. Avaliação pós-ocupação (APO): na Arquitetura, no Urbanismo e no Design: da teoria à prática. São Paulo: Oficina de Textos, 2018. cap. 5, p. 95-119.

ONO, Rosária; VILLA, Simone Barbosa; ABATE, Tania P; BARBOSA, Maria Beatriz Pestana; FRANÇA, Ana Judite Galbiatti Limongi; ORNSTEIN, Sheila Walbe. Fundamentos de APO: Método qualitativo para a aferição da percepção dos usuários. In: ONO, Rosária; ORNSTEIN, Sheila Walbe; 
VILLA, Simone Barbosa; FRANÇA, Ana Judite Galbiatti Limongi. Avaliação pós-ocupação (APO): na Arquitetura, no Urbanismo e no Design: da teoria à prática. São Paulo: Oficina de Textos, 2018. cap. 6 , p. 121-133.

ORNSTEIN, Sheila Walbe; ONO, Rosária; VILLA, Simone Barbosa; FRANÇA, Ana Judite Galbiatti Limongi. A utilização de APO para a melhoria do ambiente construído: Avaliação pós-ocupação (APO) aplicada à realimentação do processo de projeto. In: ONO, Rosária; ORNSTEIN, Sheila Walbe; VILLA, Simone Barbosa; FRANÇA, Ana Judite Galbiatti Limongi. Avaliação pós-ocupação (APO): na Arquitetura, no Urbanismo e no Design: da teoria à prática. São Paulo: Oficina de Textos, 2018. cap. 1, p. 19-41.

PENEDO, A. Arquitetura Moderna São José dos Campos. São José dos Campos/SP: Fundação Cultural Cassiano Ricardo - FCCR, 1997.

PRADO, A. K. J. A.; ROMÉRO, M. D. A.; SILVA, C. F. E. Avaliação do custo-benefício do retrofit da envoltória em um edifício público, com suporte de simulação computacional. Paranoá 22, Brasilia, 2018. 14

PRÓPRIOS Nacionais. Cadastro, atualização e avaliação dos imóveis de bens públicos da União em Santa Catarina. [S. I.], 18 fev. 2016. Disponível em: http://www.labfsg.ufsc.br/projetos-emandamento/proprios-nacionais-cadastro-atualizacao-e-avaliacao-dos-imoveis-de-bens-publicos-dauniao-em-santa-catarina/. Acesso em: 2 jul. 2020.

RAMIS, Jacqueline. Simulação Térmica da Residência H17 B - Casa Niemeyer. [S. I.: s. n.], 2019.

REIS, Mariana Chaves. THERMAL COMFORT AND ENERGY EFFICIENCY EVALUATION OF A HISTORIC BUILDING RETROFIT. Orientador: Wilson Cabral de Sousa Junior. 2020. 69 f. Dissertation (Master of Science - Course of Airport Infrastructure Engineering) - Instituto Tecnológico de Aeronáutica, São José dos Campos.

ROMERO, Marta Adriana Bustos. Princípios bioclimáticos para o desenho urbano. [S. I.]: Editora UNB, 2013.

ROMERO, M. A. B.; SILVA, C. F. E. Olhares da Reabilitação Ambiental Sustentável - Produtos das Edições do Curso de Especialização Reabilita. 1ª edição. ed. Brasília - DF: [s.n.], 2012.

ROMERO, M. D. A.; ORNSTEIN, S. W. Avaliação Pós Ocupação - Métodos e Técnicas Aplicados à Habitação Social. Porto Alegre: ANTAC, 2003.

SANCHES, Mariana. Aplicação de selo AQUA-HQE em casa dos anos 50 é inovação do Projeto Habitas. Revista USE, [s. I.], 27 mar. 2020. Disponível em: http://www.revistause.com.br/aplicacao-deselo-aqua-hqe-em-casa-dos-anos-50-e-inovacao-do-projeto-habitas/. Acesso em: 19 abr. 2020

SEGAUD, M. Antropologia do Espaço - Habitar, fundar, distribuir, transformar. São Paulo: Edições Sesc São Paulo, 2016.

SOARES GONÇALVES, J. C.; BODE, K. Edifício Ambiental. São Paulo: Oficina de Textos, 2015.

VALENEWS. ITA abre exposição Habitas e apresenta o passo a passo do retrofit sustentável da Casa Niemeyer. Valenews, [S. I.], 23 fev. 2021. Disponível em: https://valenews.com.br/2021/02/23/ita-abreexposicao-habitas-e-apresenta-o-passo-a-passo-do-retrofit-sustentavel-da-casa-niemeyer/. Acesso em: 26 mar. 2021.

VILLA, Simone Barbosa; ONO, Rosária; FRANÇA, Ana Judite Galbiatti Limongi. Fundamentos de APO: Procedimentos metodológicos. In: ONO, Rosária; ORNSTEIN, Sheila Walbe; VILLA, Simone Barbosa; 
FRANÇA, Ana Judite Galbiatti Limongi. Avaliação pós-ocupação (APO): na Arquitetura, no Urbanismo e no Design: da teoria à prática. São Paulo: Oficina de Textos, 2018. cap. 4, p. 81-92.

\section{Leandra Carneiro Marton Silva}

Arquiteta e Urbanista, especializada em Design de Interiores pela FAAP e em Reabilitação Ambiental Sustentável Arquitetônica e Urbanística pela UNB. Atualmente atua junto a OON Arquitetura, onde coordena e desenvolve tanto projetos como consultorias nas áreas de arquitetura e de interiores, aliados aos conceitos da sustentabilidade e da promoção da qualidade dos ambientes construídos.

Contribuição de coautoria: fundamentação teórico-conceitual e problematização; pesquisa de dados e análise estatística; elaboração de figuras e tabelas; elaboração e redação do texto; seleção das referências bibliográficas; revisão do texto.

\section{Marcelo de Andrade Roméro}

Arquiteto e Urbanista, Mestre, Doutor e Livre-Docente em Arquitetura e Urbanismo, Professor Sênior e Titular da Universidade de São Paulo, Pró-Reitor de Ensino do Centro Universitário Belas Artes de São Paulo.

Contribuição de coautoria: fundamentação teórico-conceitual e problematização; pesquisa de dados e análise estatística; elaboração e redação do texto; seleção das referências bibliográficas; revisão do texto.

\section{Jacqueline Elhage Ramis}

Arquiteta, Mestra em Conforto Térmico e Doutora em Eficiência Energética. Desenvolve soluções construtivas para otimizar o desempenho energético dos edifícios, promovendo economia de energia, conforto higrotérmico e lumínico, aliando arquitetura, materiais construtivos e clima locais.

Contribuição de coautoria: fundamentação teórico-conceitual e problematização, simulação computacional, seleção das referências bibliográficas e revisão do texto.

Como citar: SILVA, Leandra Carneiro Marton, ROMÉRO, Marcelo de Andrade, RAMIS, Jacqueline Elhage. Avaliação Pós Ocupação com Ênfase no Conforto Térmico: O Conjunto Habitacional de Oscar Niemeyer no Departamento Tecnológico Aeroespacial. Revista Paranoá. n.29, jan/jun 2021. DOI 10.18830/issn.1679-0944.n29.2021.07

Editores responsáveis: Caio Frederico e Silva e Daniel Richard Sant'ana 